\title{
Passive properties of the urinary bladder in the collection phase
}

\author{
R. van Mastrigt \\ B. L. R. A. Coolsaet \\ W. A. van Duyl \\ Department of Urology, Erasmus University Rotterdam, PO Box 1738, Rotterdam, The Netherlands
}

\begin{abstract}
A model is presented that describes the passive properties of the urinary bladder in the collection phase. A black-box approach is used. The system under investigation, which is defined in terms of a pressure-volume relationship, is divided into four subsystems or blocks, namely two geometry blocks, a block describing the time-dependent properties of the bladder wall, and a block describing its length-dependent properties. Models have been developed and tested for each block separately. With regard to geometry, the bladder is described as a thick-walled sphere of constant tissue volume. The time-dependence of the properties of the wall can be explained using a visco-elastic model, and the length dependence of the wall properties is shown to yield elastic moduli which depend biexponentially on strain. Estimates of the value of the parameters involved were obtained from experiments on strips of urinary bladder, obtained from the local slaughterhouse. Combination of the blocks yielded an overall model of the passive properties of the urinary bladder in the collection phase. The model contains 74 parameters. The classical way of investigating the urinary bladder, by filling it slowly and measuring the pressure produced, yields a pseudostatic pressure-volume relationship called a cystometrogram. The model predicts the form of the cystometrogram accurately. However, analysis of a classical cystometrogram enables us to determine only three parameters of our model. A better measurement method is based on stepwise (or almost stepwise) straining of the urinary bladder. One stepwise straining vields eight parameters, provided the initial volume of the bladder is known, and several measurements on one bladder at different strains enable us to determine ten parameters. The results obtained with stepwise straining are compatible with the model.
\end{abstract}

Keywords-Biomechanics, Modelling. Urinary bladder

List of symbols

$$
\begin{aligned}
a_{0} & =\text { constant in multiexponential model, } \mathrm{N} \\
a_{n} & =\text { coefficient of } n \text {th exponential (initial height } \\
& \quad \text { of exponential decay curve), } \mathrm{N} \\
e & =\text { base of natural logarithms } \\
e_{n} & =\text { relative elastic modulus } E_{n} / E(|\varepsilon|) \\
E_{n} & =\text { elastic modulus of } n \text {th spring, } \mathrm{N} / \mathrm{m}^{2} \\
E(|\varepsilon|)= & \text { sum of elastic moduli as a function of } \\
& \text { amplitude of applied strain, } \mathrm{N} / \mathrm{m}^{2} \\
|E|_{n} & =\text { elastic coefficient, } \mathrm{N} / \mathrm{m}^{2} \\
k & =\text { number of exponential terms used } \\
l & =\text { length of bladder-wall strip, } \mathrm{m} \\
l_{0} & =\text { length of bladder-wall strip unstrained, } \mathrm{m} \\
n & =\text { index number } \\
p & =\text { pressure in the bladder above barometric } \\
t= & \text { pressure, } \mathrm{N} / \mathrm{m}^{2} \\
V & =\text { time, } \mathrm{s} \\
V & \text { volume contained by bladder, } \mathrm{m}^{3} \\
V_{0}= & \text { unstrained volume of bladder, } \mathrm{m}^{3} \\
V_{t} & =\text { volume of bladder-wall tissue, } \mathrm{m}^{3} \\
\beta_{n}= & \text { elastic exponent }
\end{aligned}
$$

Received 18th November 1977

0140-0118/78/0765-0471\$1 50/0

(c) IFMBE : 1978

$$
\begin{aligned}
\gamma_{n}= & \text { relaxation constant in } n \text {th exponential term, } \\
& \mathrm{s}^{-1} \\
\varepsilon= & \text { strain } \frac{\left\{\left(1-\mathbf{1}_{0}\right) / \mathbf{1}_{0}\right\}}{1_{0}} \\
|\varepsilon|= & \text { amplitude of applied strain } \\
\eta_{n}= & \text { viscosity modulus of the dashpot, } \mathrm{Ns} / \mathrm{m}^{2} \\
\mu & =\text { Poisson's ratio } \\
\sigma & =\text { stress in bladder wall } \\
\sigma(a) & =\text { standard deviation of parameter } a, \text { relative } \\
& \text { to } a \\
\phi & =\text { sum of least squares, } \mathrm{N}^{2}
\end{aligned}
$$

\section{Introduction}

Two phases can be distinguished in the working cycle of the urinary bladder: the collection phase (in which the urine produced by the kidneys is collected in the bladder) and the evacation phase (in which the urine collected is expelled via the urethra). The bladder is dominated by different properties (both passive and active) in these two phases. By passive properties is understood to mean those properties which do not involve energy 
production by metabolism, while active properties do.

The purpose of this investigation is to describe, quantitatively, in physical terms, the passive properties of the urinary bladder in the collection phase.

These properties can be described in terms of a volume-pressure relationship. The volume and pressure interact via the bladder wall. A certain volume $V$ of fluid in the bladder strains the bladder wall to a certain degree.

The strain $\varepsilon$ is defined as:

$$
\varepsilon=\frac{l-l_{0}}{l_{0}}
$$

where $l_{0}$ is the original length (1) and $l$ is the strained length of an imaginary piece of bladder wall.

The straining of the wall causes a stress $\sigma$ in the wali, which, in turn, determines a pressure depending on the geometry of the bladder. This set of causal relations is illustrated in the model of Fig. 1. We shall investigate the functions of the various blocks of this model in separate sections.

Since bladder-wall tissue is a nonlinear viscoelastic material, which means that the output signal of the wall block depends on time as well as viscous element to a stepwise straining is a monoexponentially decaying stress (COOLSAET et al., $1975 b$ ).

Since one exponential term does not fit the measured curves adequately, the mechanical model is expanded with extra elements in parallel, each element consisting of a viscous and an elastic element in series (CHRISTENSEN, 1971). A nondecaying component represented by a single spring in parallel with the above must also be introduced. The stress resulting from a strain step can then be described as:

$$
\sigma=\sum_{n=1}^{k} a_{n} e^{-\gamma_{n} t}+a_{0} \quad . \quad . \quad . \quad . \quad . \quad .
$$

Generally we will use a model with three exponential terms and a constant as shown in Fig. 2; the arguments for this are discussed in Section 2.3.

If we measure the step response of a strip of bladder wall and fit the results with a sum of a number of exponential terms plus a constant, we obtain the coefficients $a_{n}$ and relaxation constants $\gamma_{n}$ as parameters.

Introducing the tissue volume $V_{t}$, we can relate $a_{n}$

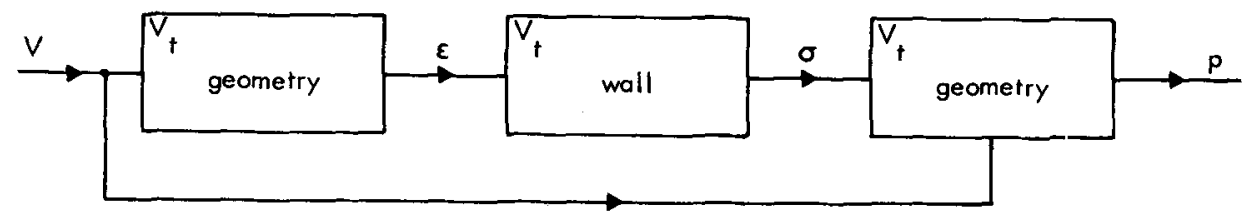

Fig. 1 Model of the urinary bladder in the collection phase

on strain or length (JAMISON et al., 1968), the wall block is split up into two subblocks describing these dependencies separately.

In Section 5 the properties of all blocks will be combined to yield one complete model.

\section{Time-dependent behaviour of the bladder wall}

\subsection{Theory}

The time-dependent behaviour of the urinary bladder wall can be investigated by experiments on isolated strips of bladder wall (COOLSAET et al., 1975b).

The total time-dependent behaviour can be determined in one measurement, and at one strain level, by straining these strips stepwise and observing the stress response (CoOlsAET et al., 1976). It is known that the urinary bladder wall has viscous as well as elastic properties (HILl, 1926; AxELSSON, 1970; AleXANDER, 1971; APTER et al., 1972).

The response of a viscoelastic series model consisting of one linear elastic element and one linear

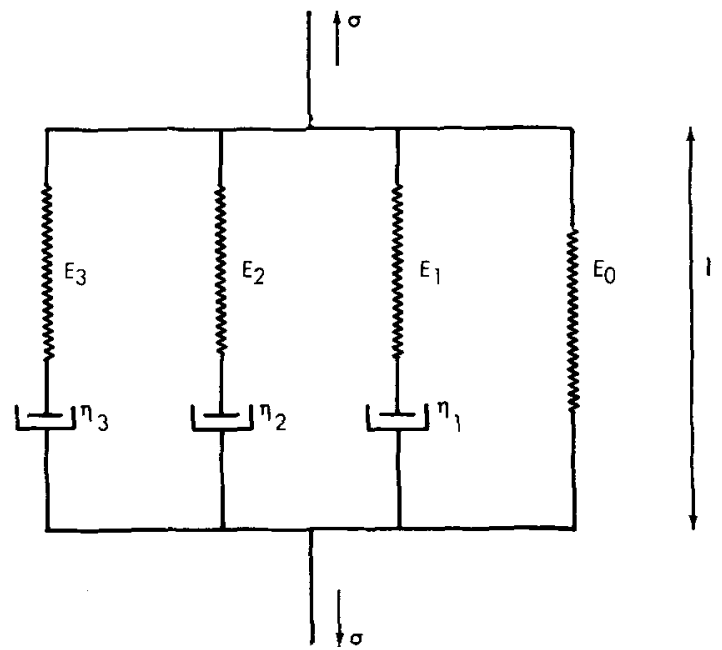

Fig. 2 Mechanical model of time-dependent strainstress response of bladder wall 
to the elastic moduli $E_{n}$ as follows (COOLSAET et al., 1975a)

$$
E_{n}=\frac{a_{n} l}{\varepsilon V_{t}} \quad . \quad . \quad . \quad . \quad . \quad . \quad . \quad .
$$

The viscosity moduli $\eta_{n}$ can be obtained from the relaxation constants $\gamma_{n}$. However, in order not to combine the standard deviations of coefficients and relaxation constants in our calculations, we will use the elastic moduli and relaxation constants as fundamental parameters. For our description of the fundamental time-dependence of the stress-strain relationship, only the relaxation constants are relevant.

\subsection{Methods}

Dog- and pig-bladder strips measuring about $10 \times 20 \mathrm{~mm}$ were strained stepwise using a pneumatic strain device (COOLSAET et al., 1976). The strips were immersed in a physiological solution which was constantly perfused, aerated with $95 \% \mathrm{O}_{2}$ and $5 \% \mathrm{CO}_{2}$ and kept at $37^{\circ} \mathrm{C}$. The measured force was digitised and fed directly into a Texas Instruments 980B minicomputer.

Experiments were performed using a number of different physiological solutions (CoOLSAET et al., 1977), but only two of these are relevant here:

(i) A modified Krebs solution ( $\mathrm{B}$ BERG and AxelsSON, 1965), which we used as standard solution; this is called the 'natural' solution below.

(ii) A solution used to reduce the influence of the active properties of the tissue. For pig bladders EGTA was used (CoOlsaet, 1977), for dog bladders D 600 (MAYER et al., 1972).

In all cases, the time that elapsed between the death of the animal and the start of the experiment was about one hour.

The original length $l_{0}$ was determined by allowing the strip to stretch under the weight of the lower clamp (mass $=13 \mathrm{~g}$ ) for about $1 \mathrm{~s}$. The measurement cycle consisted of a step to a constant strain of
0.30 maintained for $1000 \mathrm{~s}$ followed by $20 \mathrm{~min}$ rest at zero strain. About 10 measurements were taken from each strip. The curves measured were fitted with a multiexponential model using the stepwise approximation method described by van MASTRIGT (1977b) and discussed by KuIK (1976) and VAN Mastrigt (1977c).

The separation of a signal into exponentials is a very awkward problem (LANCzos, 1956). A number of models and methods were tested (VAN MASTRIGT, $1977 a$ ) as alternatives to the computational method used here, but none of them turned out to be successful.

\subsection{Results}

The basic shape of the force-time curve obtained resembles that of Fig. 3. Pig-bladder strips and sometimes also dog-bladder strips when investigated in the natural solution show a spontaneous rhythmic activity which is simply added to the curve.

When D 600 or EGTA was used, spontaneous activity was not observed. To determine experimentally the order of the system under investigation, i.e. the number of exponentials which should be used or, the value of $k$ in eqn. 2, the EGTA group of curves was fitted with an increasing number of exponential terms. The results can be seen in Fig. 4.

From the flattening off of the average sum of least squares at $k=4$ we can conclude that the order of the system is four. This has been confirmed with the aid of an $F$-test. However, some curves can obviously be fitted adequately with three exponentials (see Fig. 4, curve $S 600$ ) while others require at least five exponentials (Fig. 4, curve S 604). In fact, we shall use three exponentials and a constant to avoid 'overfitting' of curves like S 600 .

Table 1 shows the average relaxation constants and standard deviations determined for a number of measurements. Variance analysis was used to split the variance of the relaxation constants into two components. The first component is related to the differences between measurements on one strip,

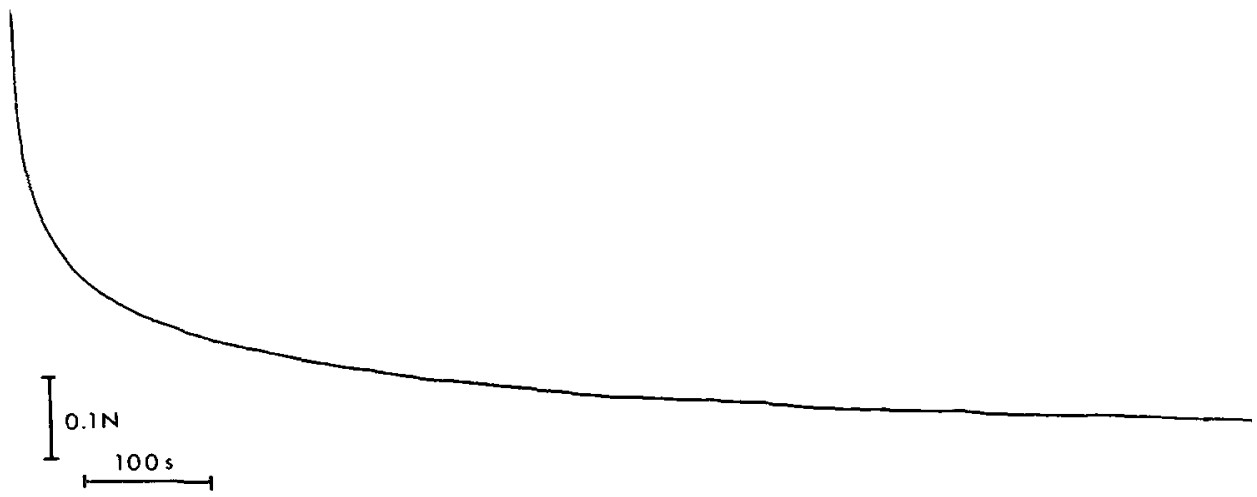

Fig. 3 Force as a function of time response to stepwise straining of a bladder-wall strip 
and is called the physiological spread. The second component concerns differences between strips and is called the biological spread. The corresponding standard deviations are shown in Table 1 for the groups 'dogs, natural' and 'pigs, EGTA'.

The lower standard deviations in the latter group are clearly caused by a lower biological spread.

We can conclude tentatively from this, that large differences between strips are probably caused by active properties only. The group 'pigs, EGTA, increasing strain' contains measurements at increasing strains between $0 \cdot 2$ and $1 \cdot 6$. From the fact that the standard deviations in this group are

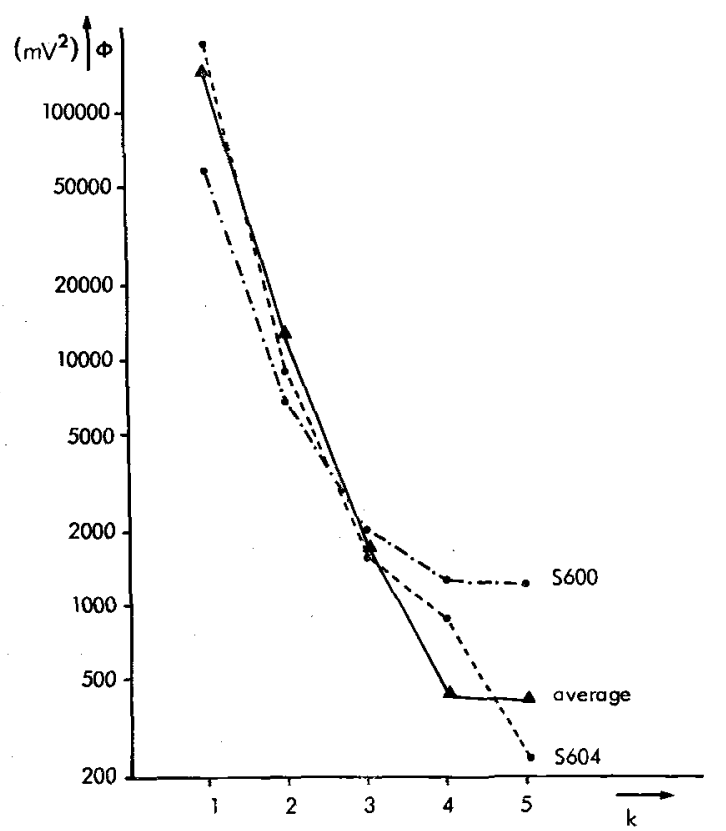

Fig. 4 Average sum of least squares as a function of number of exponentialterms fitted not significantly larger than those in the corresponding group measured at constant strain, we conclude that the relaxation constants are independent of strain. In order to test for homogeneity and isotropy, series of measurements were performed on pairs of strips taken from the same urinary bladder, but with their longitudinal axes at right angles. These measurements are shown in the last two rows of Table 1. No significant differences between the values measured could be found by Student's $t$ test or a Wilcoxon symmetry test.

\section{Length-dependent behaviour of the bladder wall}

\subsection{Pulse measurements}

3.1.1 Theory: In contrast to the relaxation constants, the elastic moduli do depend on the amplitude of

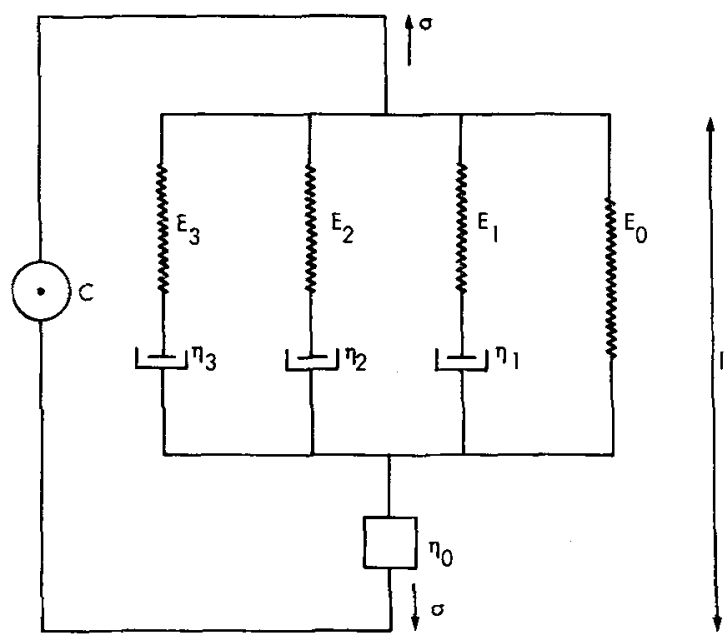

Fig. 5 Modified mechanical model with initial-length dashpot and active element

Table 1. Relaxation constants from the various groups of measurements

\begin{tabular}{|c|c|c|c|c|c|c|c|}
\hline Group & $\gamma_{1}\left(\mathbf{s}^{-1}\right)$ & $\sigma\left(\gamma_{1}\right)$ & $\gamma_{2}\left(s^{-1}\right)$ & $\sigma(\gamma)$, & $\gamma_{3}\left(s^{-1}\right)$ & $\sigma\left(\gamma_{\mathrm{s}}\right)$ & $\begin{array}{c}\text { Number of } \\
\text { measure- } \\
\text { ments }\end{array}$ \\
\hline & & $\%$ & & $\%$ & & $\%$ & \\
\hline $\begin{array}{l}\text { Dogs, natural } \\
\text { physiological spread } \\
\text { biological spread }\end{array}$ & $0 \cdot 47$ & $\begin{array}{l}66 \\
50 \\
46\end{array}$ & 0.045 & $\begin{array}{l}71 \\
59 \\
40\end{array}$ & 0.0050 & $\begin{array}{l}50 \\
46 \\
14\end{array}$ & 118 \\
\hline Dogs, D600 & 0.82 & 33 & 0.062 & 37 & 0.0037 & 30 & 26 \\
\hline Pigs, natural & $\begin{array}{c}0.23 \\
(5 \cdot 32)\end{array}$ & $\begin{array}{r}66 \\
(99)\end{array}$ & $\begin{array}{l}0.033 \\
0.14\end{array}$ & $\begin{array}{l}45 \\
28\end{array}$ & $\begin{array}{l}0.0044 \\
0.0090\end{array}$ & $\begin{array}{l}64 \\
46\end{array}$ & $\begin{array}{l}19 \\
99\end{array}$ \\
\hline $\begin{array}{l}\text { Pigs, EGTA } \\
\text { physiological spread } \\
\text { biological spread }\end{array}$ & 1.05 & $\begin{array}{r}23 \\
21 \\
8\end{array}$ & 0.077 & $\begin{array}{l}51 \\
49 \\
13\end{array}$ & 0.0061 & $\begin{array}{l}62 \\
60 \\
16\end{array}$ & 104 \\
\hline Pigs, EGTA, increasing strain & 0.96 & 27 & 0.069 & 52 & 0.0052 & 56 & 98 \\
\hline Pigs, EGTA, horizontal strip & $1 \cdot 06$ & 25 & 0.079 & 55 & 0.0063 & 65 & 48 \\
\hline Pigs, EGTA, vertical strip & 0.97 & 26 & 0.067 & 47 & 0.0054 & 52 & 48 \\
\hline
\end{tabular}


the stepwise straining

$$
E_{n}=E_{n}(|\varepsilon|) \text {. }
$$

where $|\varepsilon|$ is the amplitude of the applied strain. It turned out that when the elastic moduli were repeatedly determined at one strain level, they generally decreased; this was ascribed to a gradual increase in the rest length $l_{0}$ (COOLSAET et al., 1976).

To incorporate this behaviour in our mechanical model, we added a plastic element $\eta_{0}$ in series with the parallel combination of Fig. 2. The resetting of the plastic element is thought to be an active process, symbolised by an element $C$ (see Fig. 5). Since the observed trends in the elastic moduli were always similar, we assume that the relative elastic moduli (the elastic moduli divided by the sum of the elastic moduli) are constant.

We define:

$$
E_{n}(|\varepsilon|)=E(|\varepsilon|) \cdot e_{n} .
$$

where

$$
E(|\varepsilon|)=\sum_{n=0}^{k} E_{n}(|\varepsilon|)
$$

We call $e_{n}$ the relative elastic moduli and $E|\varepsilon|$ the elastic modulus function. The relative elastic moduli are independent of strain and can thus be determined from stepwise measurements. Table 2 contains average values of the measured relative elastic moduli and their standard deviations. The strain varied between 0.2 and 1.6 The results of measurements performed on strips cut at different angles from the urinary bladder are shown in the bottom two rows of Table 2 .

Here student's $t$ test showed significant differences $(p<0.05)$; but the Wilcoxon symmetry test did not. We conclude that there is a marginal lack of isotropy and homogeneity. The elastic modulus function cannot be reliably determined from the step-response measurements since here the increase in $l_{0}$ affects the results.

However, since we only need to know the initial height of the step-responses to determine this function, we can restrict our straining to very short periods, so that the increase in $l_{0}$ will be insignificant.
3.1.2 Methods: Strips were repeatedly strained for $625 \mathrm{~ms}$ at intervals of $62.5 \mathrm{~s}$, using the pneumatic strain device mentioned in Section 2.2. During each strain pulse the resulting force was sampled four times. The average was taken as a measure of the response to the strain level in question, and will be called the 'average peak force' from now on. Strips from the posterior wall of pig bladders were used in an EGTA solution and the initial length was determined as described in Section $2 \cdot 2$.

3.1.3. Results: The reproducibility of our method was tested by applying a series of strain pulses of amplitude $0 \cdot 30$. Since successive measurements tended to yield significantly lower responses, we concluded that the influence of the $\eta_{0}$ element was still too large. When pulses at two different strain levels were alternated, we found that the absolute differences between these peak forces were very reproducible as long as the two strain levels were not too far apart $(\leqslant 0 \cdot 3)$.

Using this information, a measurement series

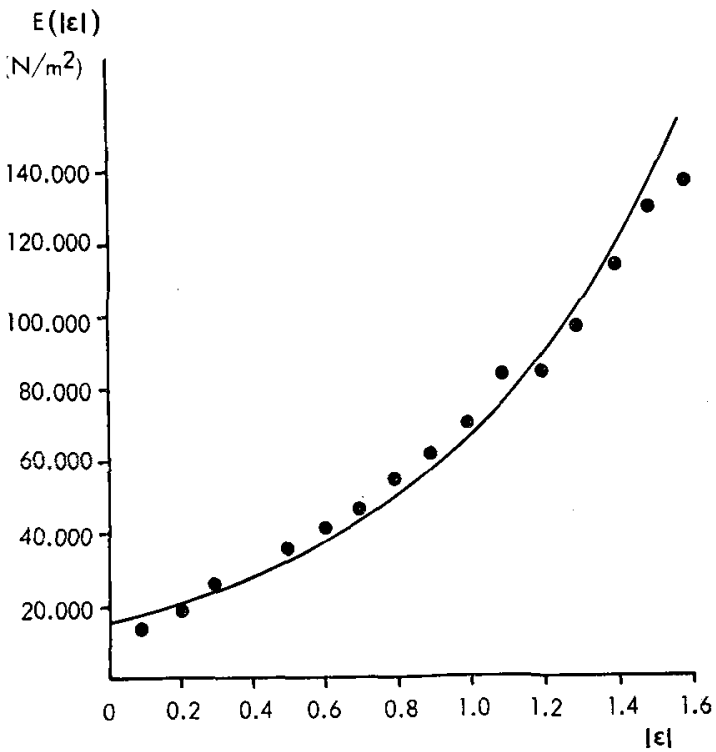

Fig. 6 Measured elastic modulus function and fitted mono-exponential function

Table 2. Relative elastic moduli and standard deviations

\begin{tabular}{lccccccccc}
\hline \multicolumn{1}{c}{ Group } & $e_{0}$ & $\sigma\left(e_{0}\right)$ & $e_{1}$ & $\sigma\left(e_{1}\right)$ & $e_{-2}$ & $\sigma\left(e_{2}\right)$ & $e_{3}$ & $\sigma\left(e_{3}\right)$ & $\begin{array}{c}\text { Number of } \\
\text { measure- } \\
\text { ments }\end{array}$ \\
\hline & & $\%$ & & $\%$ & & $\%$ & & $\%$ & \\
Pigs, EGTA, increasing strain & 0.17 & 32 & 0.50 & 19 & 0.20 & 15 & 0.14 & 22 & 98 \\
Pigs, EGTA, horizontal strip & 0.12 & 51 & 0.55 & 19 & 0.13 & 32 & 0.19 & 12 & 48 \\
Pigs, EGTA, vertical strip & 0.15 & 36 & 0.50 & 18 & 0.15 & 28 & 0.20 & 11 & 48 \\
\hline
\end{tabular}


involving increasing strain pulses with added correction pulses was designed. The elastic modulus function was computed as a function of strain according to eqn. 3 from the average peak forces measured in this way. In Fig. 6 the dots represent the values thus calculated.

A monoexponential function:

$$
E(|\varepsilon|)=|E|_{l} \exp \left(\beta_{1}|\varepsilon|\right) \quad . \quad . \quad . \quad .
$$

turned out to fit the measured data very well (Fig. 6, full line). We shall call $|E|_{I}$ the elastic coefficient, and $\beta_{1}$ the elastic exponent.

Ten measurements were performed on strips of bladder wall from seven different bladders. The parameters determined are shown in Table 3.

Table 3. Average and standard deviation for the parameters defining the elastic modulus function at low strains

\begin{tabular}{cccc}
\hline Parameter & $\begin{array}{c}\text { Average } \\
\text { value }\end{array}$ & $\begin{array}{c}\text { Relative } \\
\text { standard } \\
\text { deviation }\end{array}$ & $\begin{array}{c}\text { Number of } \\
\text { measure- } \\
\text { ments }\end{array}$ \\
\hline$\beta_{1}$ & $1 \cdot 28$ & 19 & 10 \\
$|\mathrm{E}|_{1}$ & $16084 \mathrm{~N} / \mathrm{m}^{2}$ & 43 & 10 \\
\hline
\end{tabular}

\subsection{Ramp measurements}

3.2.1 Theory: The dynamic measurements described in Section 3.1.3. could not be performed at strains higher than 1.6 because the forces involved would damage the strip.

Since the elastic moduli may deviate from a monoexponential function at high strains (VAN MASTRIGT et al., 1977d), we investigated the elastic moduli or modulus at high strains by quasi-static measurements, which yield lower forces. The error involved due to the influence of the dashpots can be estimated from the relaxation constants, which yields about $10 \%$ using the data of Section 3.2.2.

When the viscous effects can be ignored and the influence of the active element is reduced by EGTA, the model reduces to the $E_{0}$ spring in series with the $\eta_{0}$ element.

3.2.2 Methods: The pneumatic strain device mentioned in Section $2 \cdot 2$ was modified so that the strip could be strained at a constant speed by slowly paying out a steel wire, using an infusion pump.
Unless otherwise specified, the speed used was $1.66 \times 10^{-5} \mathrm{~m} / \mathrm{s}$. This means that full extension of the strip $(50 \mathrm{~mm})$ was reached in about $50 \mathrm{~min}$. Force was plotted against length and elastic modulus against strain using a Hewlett Packard point plotter, while both curves were also plotted semilogarithmically.

Parts of the curves could be fitted with a monoexponential curve using a least-squares criterion. Strips from the posterior wall of pig bladders were again used in an EGTA solution, and initial length was determined as described in Section 2.2.

3.2.3 Results: In the first experiments strips were extended up to $50 \mathrm{~mm}$ once at constant speed. The force-length plot showed sudden drops after an initial smooth rise and an irregular pattern of increasing and decreasing force at high strains. These high-strain phenomena were ascribed to the 'flow' of the plastic element $\eta_{0}$. To obtain reliable measurements of the elasticity involved, a series of quick-release experiments was performed, in which the strip was extended at constant speed up to a certain force, quickly released to force zero, and then extended again at the original speed up to a higher force. The resulting force-length plot is shown in Fig. 7.

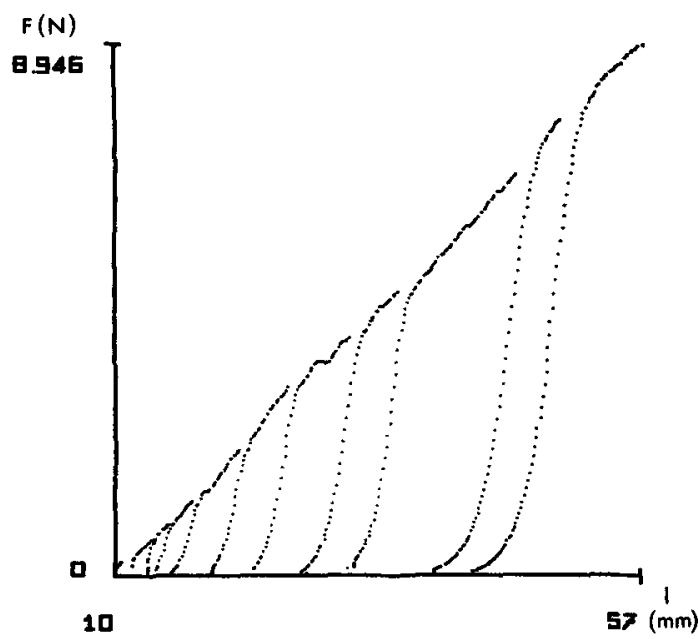

Fig. 7 Force-length plot of a strip of bladder wall strained at constant speed with repeated quick releases

Table 4.

\begin{tabular}{ccccccc}
\hline Parameter & $\begin{array}{c}\text { Average } \\
\text { value }\end{array}$ & Total & $\begin{array}{c}\text { Relative standard deviation } \\
\text { Physiological } \\
\text { spread }\end{array}$ & $\begin{array}{c}\text { Biological } \\
\text { spread }\end{array}$ & $\begin{array}{c}\text { Number of } \\
\text { curves }\end{array}$ & $\begin{array}{c}\text { Number of } \\
\text { measurements }\end{array}$ \\
\hline$\beta$, & & $\%$ & $\%$ & $\%$ & & \\
$|\mathrm{E}|_{2}$ & $1 \cdot 25 \mathrm{~N} / \mathrm{m}^{2}$ & 360 & 14 & 22 & 27 & 10 \\
\hline
\end{tabular}


It is interesting that the envelope of these curves shows the same pattern as mentioned above; however, the individual curves rising to the envelope are quite smooth and reproducible. We interpret this by assuming that the plastic element $\eta_{0}$ implies some threshold force. When the threshold force (which in these experiments equals the force at which the element last ceased to flow) is exceeded, plastic flow begins. The repeated ascending curves up to the enveloping 'plastic flow' curve would thus seem to represent elastic properties at different strains. The last two or three ascending curves from each set of measurements (depending on how close together the curves were) were fitted with a monoexponential. The results can be seen in Table 4 . Note the very high standard deviation of the elastic coefficient, which is caused by the elongation of the $\eta_{0}$ element. Variance analysis applied to the data showed that the differences between strips (biological spread) was significantly greater by $F$-test than the differences within strips (physiological spread). Note furthermore the significant difference between the value of the elastic exponent found here and that found in Section 3.1. We conclude that at high strains the elastic modulus function shows a different slope than at low strains; thus we represent the elastic modulus function by a 2exponential expression:

$$
E(|\varepsilon|)=|E|_{1} \exp \left(\beta_{1}|\varepsilon|\right)+|E|_{2} \exp \left(\beta_{2}|\varepsilon|\right)
$$

Finally, it should be noted that although we expected a viscoelastic relaxation of about $10 \%$ upon stopping the straining of the strip at these low strain speeds, as mentioned in Section 3.2.1, in fact a relaxation of about $50 \%$ was seen. This might be an indication that the time-dependent behaviour of the strip is nonlinear. This unexpected behaviour can probably be described more adequately using a continuous relaxation model instead of a discrete model. Future research on this topic is called for.

\section{Geometry of the urinary bladder}

\subsection{Theory}

In this Section we will consider the two geometry blocks of Fig. 1. Our basic assumption will be that the urinary bladder is a thick-walled hollow sphere (Osborne and Sutherland, 1909; Matsumoto and La Grange, 1973).

The first geometry block, relating volume to strain, can then be described as follows:

$$
\varepsilon=\frac{l-l_{0}}{l_{0}}=\frac{l}{l_{0}}-1=\left(\frac{V}{V_{0}}\right)^{\frac{t}{3}}-1 . . .
$$

where $V_{0}$ is the 'unstrained' volume of the bladder.

As far as the second geometry block, relating stress to pressure, is concerned, LAMÉ $(1852$, p. 212) gives a relationship for a linearised thick-walled sphere, which can be simplified (VAN MASTRIGT, 1977a) to:

$$
\sigma=\frac{3 p V}{2 V_{t}} \quad . \quad . \quad . \quad \cdot \quad \cdot \quad \cdot \quad \cdot \quad .
$$

This relationship can also be obtained by simply calculating the balance of force over two hemispheres (MATSUMOTO and LA Grange, 1973; COOlSAET et al., 1975a). If we take $V_{t}<0.1 \times V$, which is generally a fairly realistic assumption, the total error introduced by simplifying the original relation is about $10 \%$,

\subsection{Methods}

Eqn. 9-for the first geometry block-and eqn. 10- for the second-can both be tested by measuring the pressure-volume relationship of a bladder, quasistatically calculating the stress-strain relationship of the wall block from the results, and then measuring this stress-strain relationship directly on a strip of bladder wall.

Since quasistatic measurements on bladder wall are rather time-consuming, we performed the measurements on a rubber balloon which showed negligible viscosity.

The balloon was connected to the catheter and to the rest of the apparatus described in Section 5, and was submerged in water. We calculated the stress and strain for each measured set of volume and pressure values, and hence the elastic modulus, using the relationship:

$$
\sigma=2 \varepsilon E
$$

The reason for the factor 2 here is that we strain the material in all directions in the surface and not only in one as is the case with strips. It can easily be shown (see FranK, 1906, or BrodY and QUIGLEY, 1948) that in the linear case this yields a multiplicative factor of $(l / l-\mu)$, where $\mu$ equals Poisson's ratio which we assume to be $0.5\left(V_{t}\right.$ is constant). The elastic modulus was also obtained from measurements on a strip from the wall of the balloon, using the equipment described in Section 2. In both cases (total balloon and strip) measurements were first made for a small increment in strain and then for a similar decrease, and the average of the two measured values was used.

\subsection{Results}

Measurements were made on three balloons. Fig. 8 shows the pressure as a function of volume for the balloon as a whole. The average values of the elastic modulus for all measurements are tabulated in Table 5. We see that the standard 
deviation of the elastic moduli is significantly larger for the measurements on strips than for those on the balloon as a whole which means that the measured curve for strips shows a trend. The relatively small differences between the elastic moduli calculated from strip measurements and whole balloon measurements indicate that our geometry models are reasonably accurate.

\section{Evaluation of total bladder model}

\subsection{Theory}

Our overall bladder model can be obtained by combining all the blocks considered above; see Fig. 9. In this section we will test the entire model by comparing the results of measurements on whole bladders with the predicted responses.

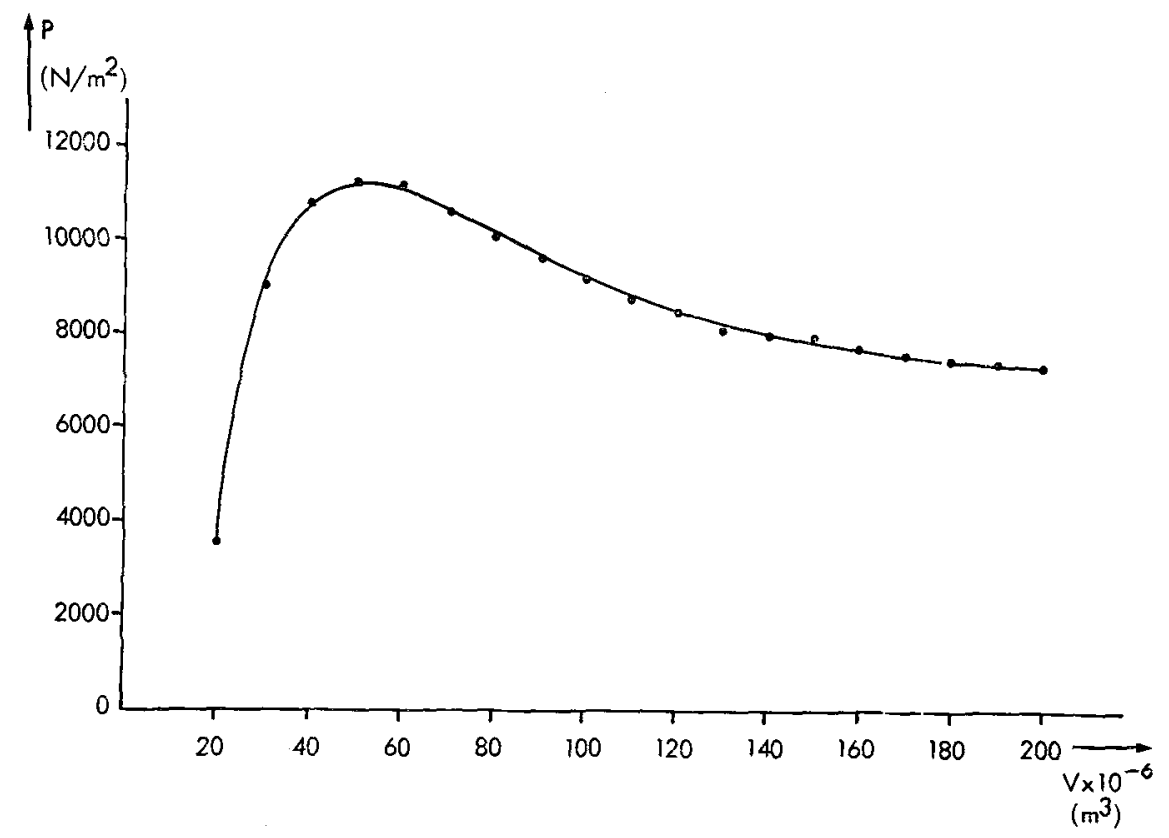

Fig. 8 Pressure as a function of volume for a rubber balloon

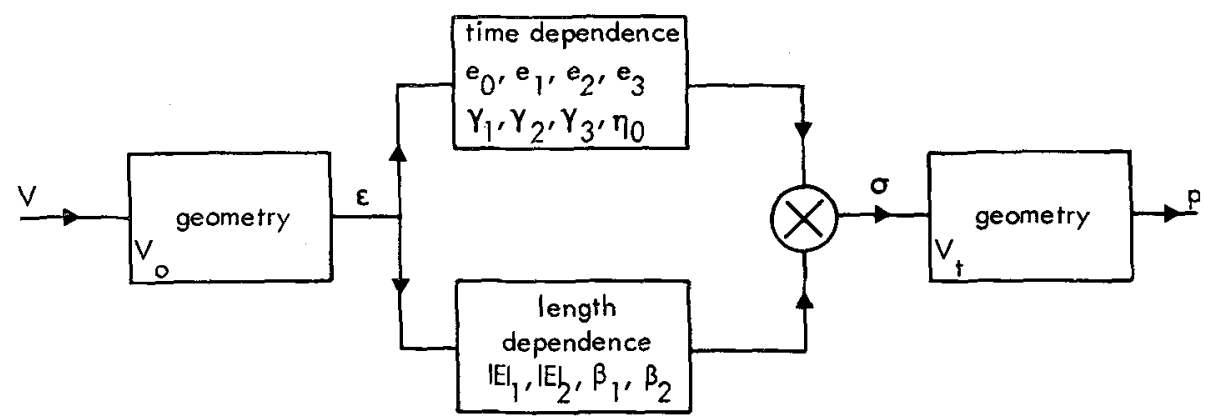

Fig. 9 Overall model of the passive properties of the urinary bladder in the collection phase

Table 5. Average elastic moduli, relative standard deviation and difference between average moduli for measurements on rubber balloons and strips of balloon

\begin{tabular}{|c|c|c|c|c|c|c|c|}
\hline \multirow[b]{2}{*}{$\begin{array}{l}\text { Measurement } \\
\text { number }\end{array}$} & \multicolumn{3}{|c|}{ Result of measurements on whole } & \multicolumn{3}{|c|}{ Result of measurements on strip } & \multirow{2}{*}{$\begin{array}{c}\text { Difference } \\
\text { between } \\
\text { average elastic } \\
\text { moduli }\end{array}$} \\
\hline & $\begin{array}{c}\text { Elastic } \\
\text { modulus }\end{array}$ & $\begin{array}{l}\text { Relative } \\
\text { standard } \\
\text { deviation }\end{array}$ & $\begin{array}{l}\text { Number of } \\
\text { measure- } \\
\text { ments }\end{array}$ & $\begin{array}{l}\text { Elastic } \\
\text { modulus }\end{array}$ & $\begin{array}{l}\text { Relative } \\
\text { standard } \\
\text { deviation }\end{array}$ & $\begin{array}{c}\text { Number of } \\
\text { measure- } \\
\text { ments }\end{array}$ & \\
\hline & $\mathrm{N} / \mathrm{m}^{2}$ & $\%$ & & $\mathrm{~N} / \mathrm{m}^{2}$ & $\%$ & & $\%$ \\
\hline 1 & 517662 & 3 & 7 & 520284 & 10 & 22 & 1 \\
\hline 2 & 427375 & 6 & 20 & 434841 & 22 & 20 & 2 \\
\hline 3 & 507359 & 5 & 19 & 455733 & 23 & 20 & 11 \\
\hline
\end{tabular}


First, we consider cystometry, which involves quasistatic filling of the bladder yielding a pressurevolume plot called a cystometrogram. With a very slow ramp as input (strain) signal, the model (see Fig. 5) reduces to the $E_{0}$ spring in combination with the $\eta_{0}$ element. Assuming that the $\eta_{0}$ element cannot follow the ramp at the low stress caused by the $E_{0}$ spring alone, we can write for the time-dependent properties of the wall

$$
\sigma=2 \varepsilon E_{0}
$$

(see eqn. 11).

Inserting the relation for the other blocks, we obtain:

$$
\begin{aligned}
p= & \frac{\left\{\left(V / V_{0}\right)^{\frac{3}{3}}-1\right\}}{V}\left[\frac{4 V_{t} e_{0}|E|_{1}}{3} \exp \left(\beta_{1}\left|\left(V / V_{0}\right)^{\frac{3}{3}}-1\right|\right)\right. \\
& \left.+\frac{4 V_{t} e_{0}|E|_{2}}{3} \exp \left(\beta_{2}\left|\left(V / V_{0}\right)^{+}-l\right|\right)\right]
\end{aligned}
$$

Fig. 10 shows the result of fitting this function to a cystometrogram measured on a pig bladder in vitro, using a least-squares criterion. The five independent parameters were determined as follows:

$$
\begin{aligned}
& V_{0}=43 \times 10^{-6} \mathrm{~m}^{3} \quad \frac{4 V_{t} e_{0}|E|_{1}}{3}=231000 \mathrm{Nm} ; \\
& \beta_{1}=0.6 \quad \frac{4 V_{t} e_{0}|E|_{2}}{3}=1.18 \mathrm{Nm} \quad \beta_{2}=5.8
\end{aligned}
$$

We see that especially the second elastic exponent agrees very well with the value measured in Section 3 .

A far more important conclusion is that the usual clinical cystometrogram gives only five parameters

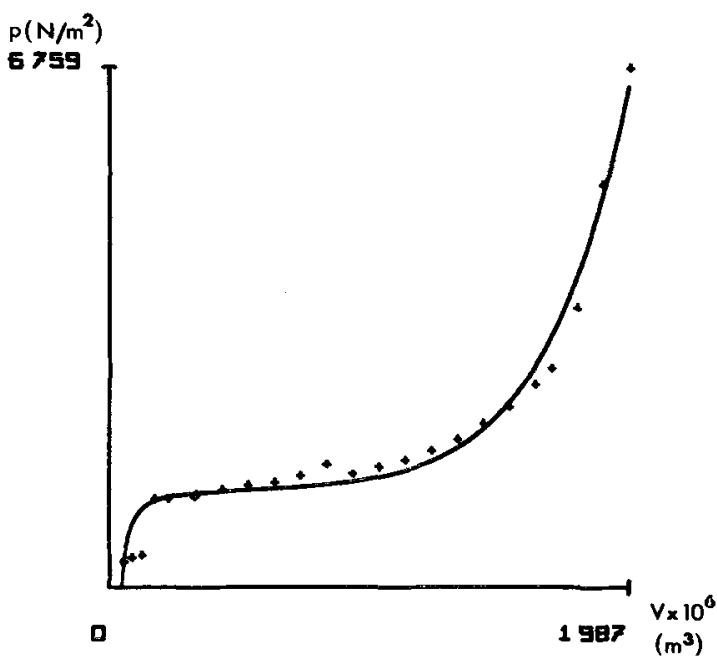

Fig. 10 Pseudostatic cystometrogram measured on a pig bladder in vitro $x-x$ and fitted function (of which two are even combinations) out of the 14 parameters which define our bladder model $\left(V_{0}, V_{t}, e_{0}, e_{1}, e_{2}, e_{3}, \gamma_{1}, \gamma_{2}, \gamma_{3},|E|_{1},|E|_{2}, \beta_{1}, \beta_{2}, \eta_{0}\right)$.

However, if we apply a stepwise volume change to the urinary bladder (COOLSAET et al., 1973) we obtain from one measurement the relaxation constants $\gamma_{1}, \gamma_{2}, \gamma_{3}$ and the relative elastic moduli $e_{0}, e_{1}$, $e_{2}, e_{3}$. To evaluate these values we have to know the tissue volume $V_{t}$. So eight parameters are needed to describe one stepwise measurement using our model. If we measure the initial volume $V_{0}$ and if we perform several measurements on one bladder at convenient strain levels, a correction as was used in Section 4 for pulse measurements can be applied. We can then also determine the elastic modulus function-only at low strains, however (because at high strains the fast straining would yield too high a pressure); this yields $|E|_{1}$ and $\beta_{1}$. This means 11 parameters are needed to describe the results of more than one stepwise measurement. In practice, since displacement of a volume of fluid always takes time, the volume change cannot be considered as stepwise even at very high filling rates.

The calculated coefficients of the multiexponential decay function will thus be too low. The coefficients of slower exponentials can be corrected, but for high strains the coefficient of the fastest exponential becomes so small that our model reduces to a 2-exponential one.

\subsection{Methods}

Experiments were performed on female mongrel dogs under continuous intravenous pentobarbital anaesthesia. Dogs were used because dog bladders show less spontaneous activity (see Section 2). Most experiments were performed with an open abdomen in order to avoid the influence of the abdominal wall.

A double lumen catheter was introduced into the bladder. The bladder was filled with physiological saline at $37^{\circ} \mathrm{C}$, at a rate of $10 \mathrm{~cm}^{3} / \mathrm{s}$, via one channel. The pressure in the bladder was measured via the other channel. The electrical pressure signal was punched on paper tape at intervals of $1 \mathrm{~s}$ for $15 \mathrm{~min}$. The initial volume of the bladder was determined by slowly filling it with a syringe. About 10 measurements were performed on each animal at intervals of fifteen minutes. The results were analysed as described in Section 2.2. After the end of the measurements the bladder was extirpated for determination of the tissue volume.

\subsection{Results}

As expected, the dog bladders showed very little spontaneous activity. Table 6 shows the average relaxation constants and their standard deviations as determined from measurements on seven dogs. These are in very good agreement with the relaxation constants measured on strips. 
As all measurements were made at a rather low strain, the experimental curves could be fitted with three exponential functions. It was not possible to draw any conclusions about the elastic modulus function, as the measurements were not performed in an order which permitted correction for the increase in rest length. However, the relative elastic moduli were still reproducible. These are shown in Table 7, and compare well with the values measured in vitro.

As in the case of strips, we see that the relative elastic moduli are more reproducible than the relaxation constants. The average initial volume was found to be $30 \mathrm{ml}$ with a relative standard deviation of $67 \%$ and the average tissue volume was $26 \mathrm{ml}$, with a relative standard deviation of $54 \%$, for the seven bladders. As there is a high correlation between these two quantities (correlation coefficient: 0.87 ), it would probably be sufficient to measure only one in practice.

\section{Conclusions}

It may be concluded that dog urinary bladders show mainly passive properties in the collection phase. Pig bladders show more active properties, but the passive properties can be described adequately in terms of the model represented by Figs. 5 and 9 and eqns. 9, 10,8 and 11. The following assumptions were made in establishing this model:

(a) All parameters which reflect properties of the bladder wall in our model are independent of the place where, and the direction in which they are measured (isotropy and homogeneity)

(b) The relaxation constants, and elastic moduli relative to their sum are constant, which implies a linear time-dependence

(c) The tissue volume of the wall is constant

(d) The urinary bladder is spherical
The model involves the following 14 parameters:

(i) The tissue volume $V_{t}$

(ii) The initial volume $V_{0}$

(iii) The relaxation constants $\gamma_{1}, \gamma_{2}, \gamma_{3}$

(iv) Four relative elastic moduli $e_{0}, e_{1}, e_{2}, e_{3}$

(v) The elastic coefficients $|E|_{1},|E|_{2}$

(vi) The elastic exponents $\beta_{1}, \beta_{2}$

(vii) One (or more?) parameters describing the behaviour of the $\eta_{0}$ element.

For all parameters except $\eta_{0}$, average values and standard deviations have been determined for dog and pig bladders. The values were obtained by various measurement techniques. The model describes the form of a 'quasistatic cystometrogram' adequately. An alternative method for testing the passive properties of the urinary bladder in the collection phase is proposed.

Acknowledgment -We would like to thank D. J. Griffiths for his help in interpreting the ramp measurements.

\section{References}

Årerg, A. K. G. and Axelsson, J. (1965) Some mechanical aspects of intestinal smooth muscle. Acta Physiol. Scand. 64, 15-27.

Alexander, R. S. (1971) Mechanical aspects of the urinary bladder. Am. J. Physiol. 220-5, 1413-1421.

Apter, J. T., MAson, P. and LANG, G. (1972) Urinary bladder wall dynamics. Investig. Urol. 9-6, 520-526.

AxELSSON, J. (1970) Mechanical properties of smooth muscle. In BŬLBRING, E. (1970) Smooth muscle Arnold.

Brody, D. A. and QUIGLEY, J. P. (1948) Some mechanical factors in the dynamics of the thin-walled, spherical viscus. Bull. Math. Biophys. 10, 25-30.

ChRISTENSEN, R. M. (1971) Theory of visco-elasticity, an introduction. Academic Press, New York.

Coolsaet, B. L. R. A., van DuYl, W. A., van Mastrigt, R. and VAN DER ZWART, A. (1973) Stepwise cystometry of urinary bladder. Urol. $\mathbf{I I}-\mathbf{3}, 255-257$.

Coolsaet, B. L. R. A., van DuYl, W. A. van Mastrigt, R. and VAN DER ZWART, A. (1975a) Visco-elastic properties of the bladder wall. Urol. Int. 30, 16-26.

Table 6. Average relaxation constants and standard deviations measured on dog bladders in vivo

\begin{tabular}{ccccccc}
\hline$\gamma_{1}\left(s^{-1}\right)$ & $\sigma\left(\gamma_{1}\right)$ & $\gamma_{2}\left(s^{-1}\right)$ & $\sigma\left(\gamma_{2}\right)$ & $\gamma_{3}\left(s^{-1}\right)$ & $\sigma\left(\gamma_{3}\right)$ & $\begin{array}{c}\text { Number of } \\
\text { measurements }\end{array}$ \\
\hline 0.45 & $\%$ & & $\%$ & & $\%$ & \\
\hline
\end{tabular}

Table 7. Average relative elastic moduli and standard deviations measured on dog bladders in vivo

\begin{tabular}{ccccccccc}
\hline$e_{0}(-)$ & $\sigma\left(e_{0}\right)$ & $e_{1}(-)$ & $\sigma\left(e_{1}\right)$ & $e_{2}(-)$ & $\sigma\left(e_{2}\right)$ & $e_{3}(-)$ & $\sigma\left(e_{3}\right)$ & $\begin{array}{c}\text { Number of } \\
\text { measurements }\end{array}$ \\
\hline 0.17 & $\%$ & & $\%$ & & $\%$ & & $\%$ & 44 \\
\hline
\end{tabular}


CoOlsaet, B. L. R. A., van Duyl, W. A., van Mastrigt, R. and Schouten, J. W. (1975b) Visco-elastic properties of bladder wall strips. Investig. Urol. 12-5, $351-356$

Coolsaet, B. L. R. A., van Mastrigt, R., van Duyl, W. A. and HuYgen, R. E. F. (1976) Visco-elastic properties of bladder wall strips at constant elongation. ibid. 13-6, 435-440.

Coolsaet, B. L. R. A. (1977) Stepwise cystometry. A new method to investigate properties of the urinary bladder. Thesis, Erasmus University Rotterdam, The Netherlands.

Frank, O. (1906) Die Analyse Endlicher Dehnung und die Elastizität u.s.w. Annal. Physik., 602-608.

Hill, A. V. (1926) The viscous elastic properties of smooth muscle. Proc. Roy. Soc. 100, 108-115.

Jamison, C. E., Marangoni, R. D. and Glaser, A. A. (1968) Visco-elastic properties of soft tissue by discrete model characterization. J. Biomech. 1, 33-46.

KuIK, A. J. (1976) Estimation of the parameters of a multi-exponential signal. Afstudeerverslag deel $I$, Laboratorium voor Technische Natuurkunde, Delft, The Netherlands.

LAmÉ, M. G. (1852) Leçons sur la theorie mathematique de l'elasticité des corps solides. Paris, Bachelier, Imprimeur-libraire du Bureau des Longitudes et de L'ecole Polytechnique.
Lanczos, C. (1956) Applied analysis. Prentice Hall, New York.

Mastrigt, R. VAN (1977a) A systems approach to the passive properties of the urinary bladder in the collection phase. Thesis, Erasmus University Rotterdam, Rotterdam.

MASTRIGT, R. VAN (1977b) Constant step approximation of multi-exponential signals using a least square criterion. Comput. Biol. Med. 7, 231-247.

Mastrigt, R. VAN (1977c) A short note on the performance of two computer programs for the estimation of the parameters of a multi-exponential model. ibid. 7, 249.

Mastright, R. van, Coolsaet, B. L. R. A. and Duyl, W. A. VAN $(1977 d)$ The passive properties of the urinary bladder in the collection phase. Urol. Int. to be published.

Matsumoto, Y. and LA Grange, R. (1973) Dog bladder pressure-volume relation determined from isolated strip of wall muscle, force-length curve. Life Sci. 12, I.

Mayer, C. J., Breemen, C. van and Casteels, R. (1972) The action of lanthanum and D600 on the calcium exchange in the smooth muscle cells of the guinea-pig, Taenia coli. Pflügers Archiv. 337.

Osborne, W. A. and Sutherland, W. (1909) The elasticity of rubber balloons and hollow viscera. Proc. Roy. Soc. B 81, 485-499.

\section{Les propriétés passives de la vessie durant la phase de collecte}

Sommaire-Cet article présente un modèle décrivant les propriétés passives de la vessie durant cette phase de collecte. Une technique genre "boîte noire" est utilisée. Le système étudié, qui est défini en terme d'une relation pression/volume, est divisé en quatre sous-systèmes out blocs à savoir deux blocs géométriques, un bloc décrivant les propriétés des parois de la vessie en fonction du temps et un bloc décrivant les propriétés en fonction de sa longueur. Les modèles ont été mis au point et testés pour chaque bloc séparément. En ce qui concerne la géométrie, la vessie est décrite comme une sphère à parois épaisses dont les tissus ont un volume constant. La dépendance des propriétés de ces parois en fonction du temps peut être expliquée avec un modèle visco-élastique, tandis qu'on peut montrer que la relation entre les propriétés de ces parois et leur longueur correspond à des modules élastiques qui dépendent des tensions de manière biexponentielle. Les valeurs estimées des paramètres en question ont été obtenues à la suite d'expériences réalisées sur des bandes de vessies obtenues auprès de l'abattoir local. La combinaison des blocs a donné un modèle global des propriétés passives de la vessie dans la phase de collecte. Ce modèle contient quatorze paramètres. La manière classique d'étudier la vessie, qui consiste à la remplir lentement et à mesurer la pression obtenue, donne une relation pression/volume pseudo-statique appelée un cystométrogramme. Le modèle prédit précisément la forme du cystométrogramme. Cependant, l'analyse d'un tel cystométrogramme classique ne nous permet de déterminer que trois paramètres de notre modèle. Une meilleure méthode de mesure consiste à mettre sous tension de manière graduelle (ou presque) la vessie. Cela permet d'obtenir huit paramètres, pourvu que le volume initial de la vessie soit connu, et plusieurs mesures sur une vessie à différentes tensions nous permettent de déterminer dix paramètres. Les résultats obtenus avec cette méthode de mise sous tension par étape sont compatibles avec le modèle. 


\section{Passive Eigenschaften der Harnblase in der Sammelphase}

Zusammenfassung-In diesem Artikel wird ein Modell dargestellt, das die passiven Eigenschaften der Harnblase in der Sammelphase beschreibt. Es wird eine Blackbox-Methode angewandt. Das zu untersuchende System, das als ein Druckvolumenverhältnis definiert wird, wird in vier Teilsysteme oder Spalten aufgeteilt, d.h., zwei Geometriespalten, eine Spalte, die die zeitabhängigen Eigenschaften der Blasenwand darstellt, und eine Spalte, in der die längenabhängigen Eigenschaften beschrieben werden. Für jede Spalte wurden getrennte Modelle konstruiert und getestet. In bezug auf die Geometrie wird die Blase als dickwandige Sphäre mit konstantem Gewebevolumen beschrieben. Die Zeitabhängigkeit der Wandeigenschaften kann anhand eines visko-elastischen Modells erklärt werden. Die Längenabhängigkeit der Wandeigenschaften erweist sich als Erzeuger elastischer Moduli, die bi-exponentiell von der Belastung abhängig sind. Schätzungen der zugehörigen Parameterwerte erhielt man aus Experimenten nit Streifen der Harnblase, die man vom örtlichen Schlachthof bezogen hatte. Die Kombination der Spalten ergab ein Gesantmodell der passiven Eigenschaften der Harnblase in der Sammelphase. Durch die klassische Untersuchungsmethode der Harnblase, sie langsam zu füllen und den hierdurch erzeugten Druck zu messen, erhält man ein pseudo-statisches Druckvolumenverhältnis, Zystometrogramm genannt. Das Modell ergibt eine genaue Voraussage des Zystometrogramms. Jedoch kann man durch die Analyse des klassischen Zystometrogramms nur drei Parameter unseres Modells bestimmen. Ein besseres Meßverfahren beruht auf der stufenweisen (oder fast stufenweisen) Belastung der Harnblase. Eine stufenweise Belastung ergibt acht Parameter vorausgesetzt, daß das Anfangsvolumen der Blase bekannt ist. Mehrere Messungen an einer Blase bei verschiedenen Belastungen ermöglichen es uns, zehn Parameter zu bestimmen. Die Resultate der stufenweisen Belastung sind mit dem Modell vergleichbar. 